\title{
Personal wisdom development involves suffering: Experimental Validation
}

\author{
Ankita Sharma \\ Associate Professor (Psychology) \\ Indian Institute of Technology Jodhpur \\ ankitasharma@iitj.ac.in
}

Personal growth occurs with life experiences and most importantly handling and reflecting on negative life experiences teaches us more (Mickler \& Staudinger, 2008; Staudinger \& Gluck, 2011). The distinction between personal and general wisdom is based on the differences in the development process and happiness-satisfaction distinction. This article argues that personal wisdom development involves pain and suffering (Staudinger \& Kunzmann, 2005) yet feels more satisfying in retrospect. The wisdom literature so far is focused on understanding the concept which is majorly correlational, and recommendations are to study the idea experimentally so the concept can be brought to the intervention arena. Therefore, the present study attempts to explore, 'the effect of personality disposition (emotional regulation, reflectiveness, openness to experiences and action orientation) in decision making and affect handling (regret handling) as an indicator of wisdom. Precisely, 1) if people with different personality disposition differ in the choices, exploring the alternatives and handling regret in the face of failure; 2) if people with higher action orientation chose a risky option and if this choice results into failure how do they handle and finally, 3) does personality disposition predict regret handling. The objective was explored by applying SAWS questionnaire, Action Orientation questionnaire, and share the market task. The results suggested that openness to experience, and preoccupation vs. disengagement, hesitation vs. initiative dimension of action orientation significantly influences choice-making and comparatively less regret experience. Additionally, individual high on openness and action orientation explore more alternative, choose risky options and report less regret if faced with failure. The common explanation for less regret after failure may revolve around the theme of 'at least I tried'. The mediator regression analysis suggested that the individuals with initiative tendencies regret less, similarly, people with an openness to experience also regret less than their counterparts. However, individuals with high initiatives and openness to experience regret more in comparison to people with only openness or initiative tendencies. This experimental evidence confirms the observation that individuals who are open to different experiences and take specific actions to try new things will face more ups and downs and experience more regret. 
Keywords: Personal wisdom development, Openness, Action-orientation, Decision making task, Failure and regret

\section{Introduction}

The importance of life experience in the development of wisdom is recommended by most of the wisdom researchers. Weststrate and Gluck (2017) Webster (2013) discussed the importance of appropriate reflective process on the already occurred life event in the development of wisdom. However this paper contends that the way a person approaches the life (approach toward life: openness and action orientation) leads to more pain/frustration/regret in general, yet in retrospect, this feels more satisfying. This may be a common narrative in the development of wisdom through negative life experiences.

\section{Wisdom as the development of self and ego:}

Webster (2007) defines wisdom as "the competence in, intention to, and application of critical life experiences to facilitate the optimal development of self and others". Optimal development of self may follow two dimensions of positive personality development across the life span, 1) personality development toward adjustment, and 2) personality development toward growth (Staudinger \& Kunzmann, 2005). Staudinger and Kunzmann (2005) proposed that personality development toward adjustment comes as a result of coping with the normative developmental tasks and it increases affect balance, conscientiousness, agreeableness, and emotional stability (Digman, 1997). Another dimension, i.e., personality development toward growth involves life experiences that go beyond social requirements, expectations and structures. Personality growth involves an increase in openness to experience and the psychological wellbeing dimensions autonomy, personal growth and purpose in life (Wink \& Staudinger, 2015).

Now, this personality growth resounds with the conceptualization of wisdom as defined by the majority of researchers. In personality psychology, it is, for instance, Maslow's self-actualizing individual or Allport's criteria of a wise person that are often cited as references for the definition of personality growth. They suggested that criteria for a wise person included, e.g., the extension of the sense of self, capacity for intimacy, emotional security, realistic perception, self-objectification (insight and humour), unifying philosophy of life and religion. Rogers defined personal maturity as fully functioning person who is open to experience, able to live existentially, trusts in his/her organism, expresses feelings freely, acts independently, is creative, and lives a prosperous life. 


\section{Wisdom development from adverse life experiences:}

Approximately 15 years ago, Staudinger and Kunzmann (2005) argued that wisdom (especially personal wisdom) does not necessarily come with happiness and may result from overcoming adverse challenging life events. Similar ideas are supported by Mickler and Staudinger (2008), Staudinger and Gluck (2011), and Westsrate and Gluck (2017). Webster (2013) discussed the role of critical life experiences in addition to reminiscing and reflecting on those life experiences in the development of wisdom.

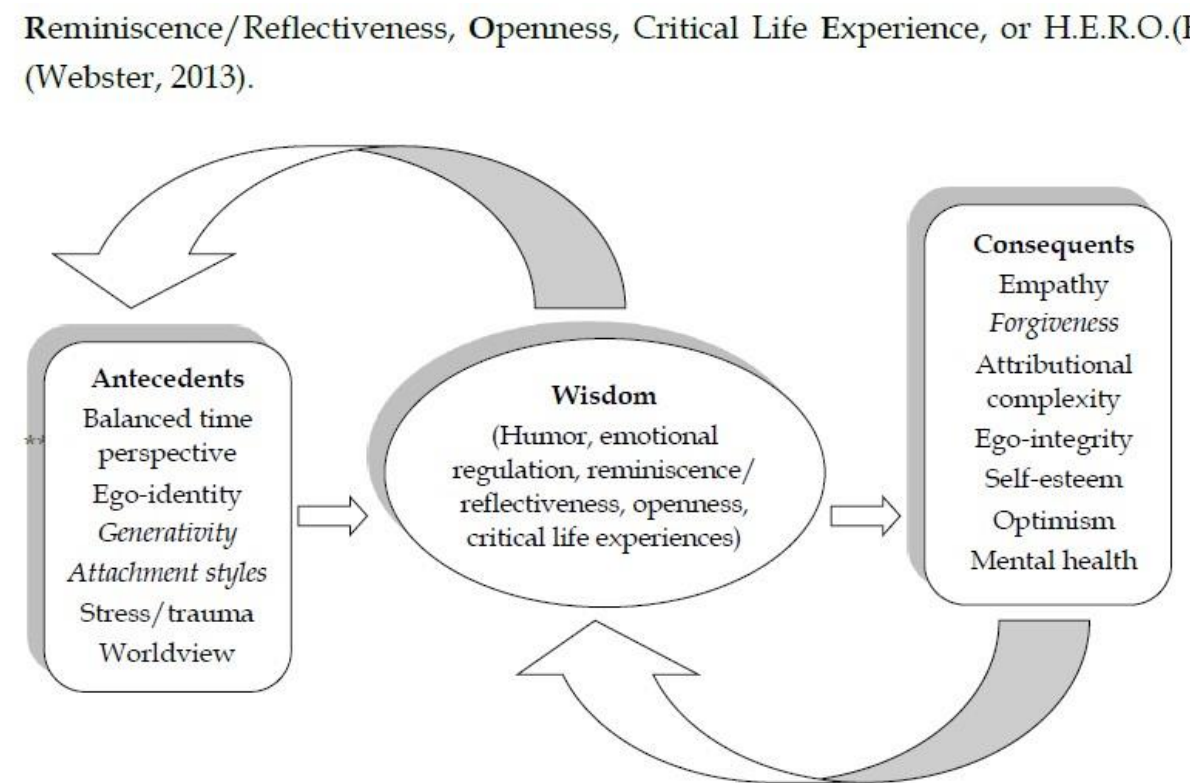

Figure 1 Antecedent and consequent variables of wisdom development

Mckee and Barber (1999) said that wisdom is hard-won from engagement with life and therefore gained through experience. In the similar line, Westsrate and Gluck (2017) concluded that wisdom fostering forms of self-reflection requires that individual explored their role in the occurrence of adverse life event, confront and examine negative feelings and do the effortful work of finding meaning in difficult life experiences.

However, the point is that one aspect of life experience is how a person processes it after the event has occurred. However, the other aspect is that how an individual approach any particular life event. The pre-experience inclination can be an essential aspect as an antecedent to wisdom development.

\section{Wisdom and approach toward life events:}

The humanistic approach of personality growth includes the openness to experience as an essential antecedent for the personality growth-related development and in turn, wisdom. 
With the experiences the personality traits of openness, conscientiousness increases and leads to the development of wisdom.

Openness to experience has been implicated in most of the conceptualization of wisdom which is generally defined as receptivity to new experiences and ideas. A related idea (which is taken as part of openness itself in Big Five Theory) is action orientation. Action orientation is defined as an individual's tendency for the self-motivated initiation and maintenance of intention related to flexible responses to a demanding situation. Now putting this in the context of an individual's approach toward any event marks a very different trajectory one may have.

The Personality System Interaction (PSI) theory by Kuhl (2000) suggests that individuals are prone toward either an action or state orientation, and this is stable personality characteristics for all persons. Action-oriented people tend to approach an event and involve more cognitive resources and thus have a higher chance of achieving goals. Nevertheless, also can handle their emotions more effectively in the face of an adverse event and in turn overcome the regret and involve with next event with same/more effort. On the contrary people with the state-orientation focus more on the negative aspect of event/possible outcome and thus prefer not to do anything about it. However, they still feel more regret in comparison to people with action tendency in the face of a negative outcome (McElroy \& Dowd, 2007; Grass et al., 2018). The concept of action orientation is not explored concerning wisdom but appears closely linked as per the conceptualization.

\section{Emotional reaction-handling, action orientation and Wisdom}

Wisdom is not only a cognitive process; it generally includes the affective regulation; a synthesis of cognitive and affective capacity. The affective component mostly describes the ability to handle emotions of oneself and others, using emotions effectively. This again connects with action orientation. According to Kuhl (1981, 1994b, 2000), action orientation is the capacity to regulate the emotions, thoughts and behaviours to fulfil their intentions, whereas, state orientation refers to the inability to do so.

De Lange and Van Knippenberg (2009) also supported that the action orientation enables individuals to shift their emotional state optimally, as a means to fulfil their goals. The disengagement versus preoccupation dimension of this orientation can strongly correlate to the handling and curbing negative affect. According to Moss (2016), individuals with disengagement action orientation show two qualities which help them in curbing adverse affects. First, these people can more easily access and activate their personal values, priorities, inclinations and perceptions of themselves. Secondly, they associate this sense of self with the feeling of agency. The hesitation versus initiative dimension can create a mechanism to foster positive emotions. The hesitant state-oriented individuals form a deficient intention (Kuhl, 1994a; Kuhl \& Goschke, 1994; Kuhl, \& Helle, 1994); and the antecedent to this deficient intention could be due to their felt obligation to enact behaviours that do not necessarily align with their preferences (Stiensmeier-Pelster \& Schurmann, 1994). 
Kazen, Kaschel and Kuhl (2008) reported that hesitation state orientation corresponds to the inability to foster the positive affect that is needed to initiate intentions.

A connected concept of inaction inertia is the inclination of individuals to reject a reasonable offer if they recently missed a better opportunity. This effect was proved in the study by Van Putten, Zeelenberg and Van Dijk (2009). However, they also reported that this effect diminishes with the action-orientation of an individual. Zeelenberg and colleagues (2006) explained 'action effect', as an action that leads to failure will cause more regret than inaction that leads to similar failure.

Therefore the approach toward an event may get determined by an individual's openness and action orientation; again, the reaction to the outcome of the event is influenced by these tendencies. The possibility is that the individual with openness and action orientation may become inclined toward experiencing more even when they face negative consequences. This does not mean that experienced pain/frustration will not be there. However, these individuals will be better at handling them and moving ahead. This may lead to happiness in the short term but increase in satisfaction in retrospect and wisdom development in the long run.

\section{Wisdom as Affect handling and SWB: Experience and remembering self}

In context to the relation of wisdom and personality, Staudinger, Dorner and Mickler (2005) commented that on one hand researches provide the evidence for positive association of ego levels with highly adaptive personality characteristics as well as mental health. Similarly, on the other hand, the ego level is also positively related to lifetime psychiatric visits and regular psychotherapy sessions. The literature of the relation between wisdom and wellbeing also suggest that general wisdom shows a small but significant relationship, whereas, personal wisdom does not relate to SWB (Mickler \& Staudinger, 2004). Mickler and Staudinger (2008) define personal wisdom as the realization of one's own potential while considering the wellbeing of others and society. This contradictory finding may be explained by the point that while being better able to provide advice to others may be associated with better SWB, higher levels in self-related insight and wisdom seem to come at a cost in terms of SWB.

The conflicting results about the relationship between wisdom and wellbeing can be understood in terms of personality adjustment and personality growth vis-à-vis subjective wellbeing and psychological wellbeing. Also, the answer could be in the distinction between experiencing self and remembering self. Kahneman (2013) explains that at the moment, affect experience (happiness) and life satisfaction (the usual indicator of SWB) is different because life satisfaction is always in retrospect. So an experience which is painful at the moment (experiencing self) may seem very satisfying in retrospect (remembering self). Therefore leading to happiness-satisfaction distinction and thus, a current painful experience may be evaluated satisfying, insight enhancing (wisdom development) in retrospect. 


\section{Rationale and assumption:}

There are several different definitions of wisdom, however; the definitions given by Jeste et al. (2010), Baltes and Staudinger (2000) and Yang (2008) is personally more convincing to me. Thus the operational definition for my work is conceptualized by combining their definition as,

"Wisdom is a form of advanced development and integration of cognition, emotion, and self, driven by life experiences and results in ways and means of understanding, planning and managing good life for self and others."

Following this definition in my previous works (Sharma \& Dewangan, 2017 \& 2018) has to lead to an understanding that people relate specific values and characteristics with wisdom and openness to experience does closely relate to the development of wisdom. I also agree with the values of insights learned from life experiences, especially by negative one (Westrate \& Gluck, 2017). However, here I argue that individual also has a role in (a) putting themselves in the situation to have more experiences, (b) taking active role/reaction to the situation, and (c) handle the situation in such a way that promotes further engagement with other experiences.

\section{Objective}

Therefore, present work, 'examines the effect of personality disposition (emotional regulation, reflectiveness, openness to experiences and action orientation) in decision making and affect handling in negative experience (regret handling). The objective is based on the assumption that this provides insight into the process through which personal wisdom may develop.

Precisely,

1) If people with different personality disposition differ in the choices, exploring the alternatives and handling regret in the face of failure;

2) If people with higher action orientation chose a risky option and if this choice results into failure how do they handle and finally,

3) Does personality disposition predict regret handling?

\section{Methodology}

Sample: The participants in this work were students and working professionals with a minimum education level of graduation. After removal of incomplete data and outliers the final total sample size is 77 (mean age $=27.05$ ), Male $=45$ and Female $=32$. 
Tools:

- $\quad$ Self-assessment wisdom scale developed by Webster, J.D. The questionnaire conceptualizes five factors in wisdom as Experience, Emotional regulation, Reflection, Humor, and Openness. The reliability (alpha value) for the current sample is 0.78 .

- Action orientation scale developed by McElory and Dowd. The scale measures the action orientation on three dimensions: Preoccupation vs. Disengagement, Hesitation vs. Initiative, and Volatility vs. Persistency. A higher score on scale denotes action orientation. The reliability (alpha value) for the current sample is 0.95

- $\quad$ Share market task by McElroy and Keith Dowd (2007) was used, followed by a reflective interview for the thought during the task. Participants had to choose between one of two company stock options which will make the most profit. These options differ on their level of risk. Participants read that if they keep stock in Company X, they will make an e.g. profit of 2,000 (safe option). Alternatively, if they choose to switch to stock in Company Z, they would have a one-third probability of making an e.g. 6,000 profit and a two-thirds probability of making no profit (risky option). After participants made their choice, feedback is given. For all participants, this feedback indicated that they would have been better off choosing the option that they did not select. The second round of the same decision to choose between two company stock option is conducted. Here the participant can choose to stay with the previous choice or change the choice to other stock. Here again, no matter what the decision was; negative feedback was given. After every round of task, a visual analogue of regret on 100 point scale was taken.

\section{Result and Discussion}

This article explores the empirical evidence for the argument that an individual's personality disposition may make them inclined toward approaching life experiences, handling negative consequences better and hence, they continue to maintain this inclination. Also, this whole approach will lead to increased negative emotional experience at the moment but will lead to wisdom development in the long term. Thus to get the empirical evidence for these assertions three specific questions were asked: 1) If people with different personality disposition differ in the choices, exploring the alternatives and handling regret in the face of failure; 2) If people with higher action orientation chose a risky option and if this choice results into failure how do they handle and finally, 3) Does personality disposition predict regret handling.

In the analysis for question one and two, the mean differences were analyzed. No significant results were found for emotional regulation, reflection and humour dimension of wisdom and volatility vs persistency dimension of action orientation. However, the significant result for openness (wisdom), preoccupation vs disengagement, hesitation vs 
initiative (action orientation), choices and regret (decision making task), provides useful insight and evidence for the assertion of this paper.

Table-1. Mean score differences of predispositions for safe $(n=61)$ versus risk $(n=16)$ option taken by the participants $(\mathrm{N}=77)$ in the first trial of share market task.

\begin{tabular}{|lcccccc|}
\hline & \multicolumn{9}{c}{ Safe Option (n=61) } & \multicolumn{2}{c}{ Risk Option (n=16) } & & \\
\cline { 2 - 4 } $\begin{array}{l}\text { Personality } \\
\text { Dispositions }\end{array}$ & Mean & SD & Mean & SD & t & p-value \\
$\begin{array}{l}\text { Preoccupation vs } \\
\text { Disengagement }\end{array}$ & 5.05 & 2.99 & 7.27 & 2.67 & -2.68 & 0.009 \\
$\begin{array}{l}\text { Hesitation vs } \\
\text { Initiative }\end{array}$ & 6.43 & 2.61 & 6.89 & 3.34 & -0.58 & 0.566 \\
SAWS_Openness & 28.85 & 7.87 & 34.38 & 5.32 & -2.67 & 0.010 \\
\hline
\end{tabular}

Figure-1.Mean score differences of predispositions for safe $(n=61)$ versus risk $(n=16)$ option taken by the participants $(\mathrm{N}=77)$ in the first trial of share market task.

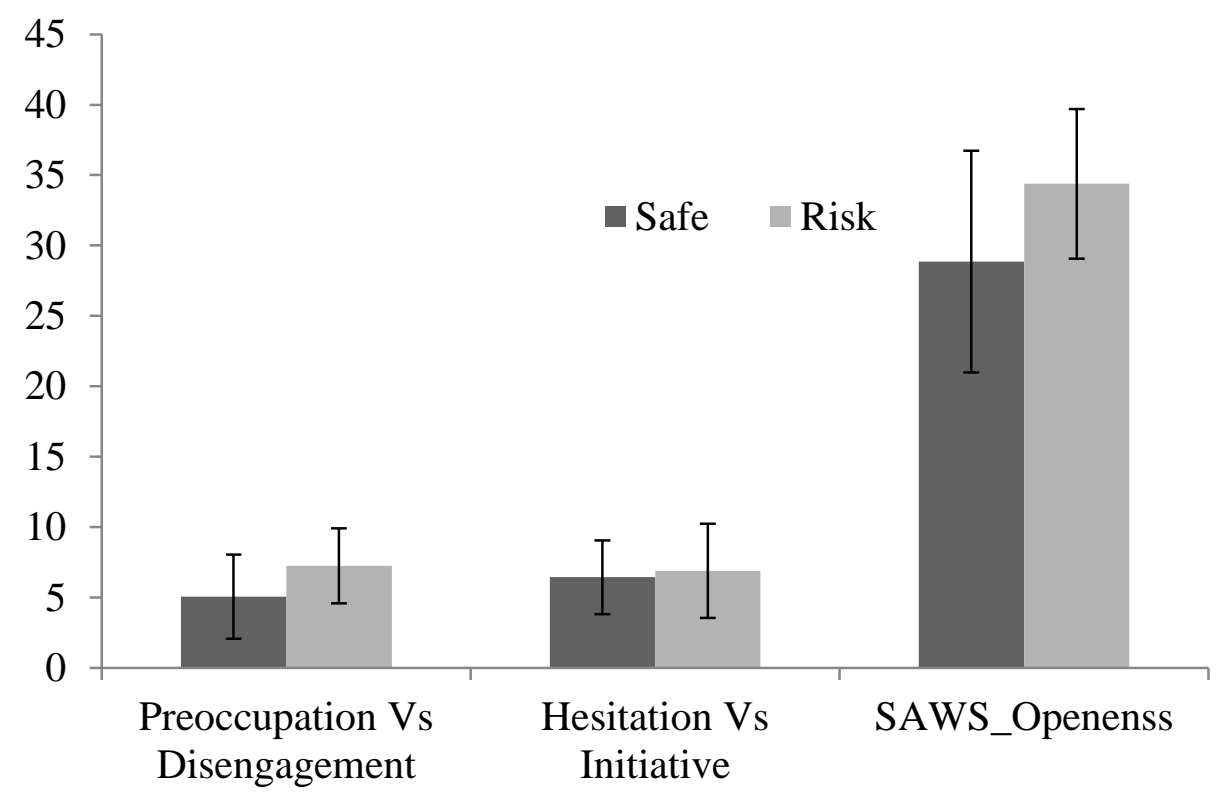


Table-2. Mean score differences of predispositions for safe $(n=51)$ versus risk $(n=26)$ option taken by the participants $(\mathrm{N}=77)$ in second in the trial of share market task

\begin{tabular}{|ccccccc}
\hline $\begin{array}{c}\text { Personality } \\
\text { Dispositions }\end{array}$ & Mean & SD & Mean & SD & T & p-value \\
\cline { 2 - 5 } $\begin{array}{c}\text { Preoccupation vs } \\
\text { Disengagement }\end{array}$ & 4.98 & 2.98 & 6.54 & 2.94 & -2.18 & 0.033 \\
$\begin{array}{c}\text { Hesitation vs } \\
\text { Initiative }\end{array}$ & 6.18 & 2.54 & 7.19 & 3.09 & -1.54 & 0.128 \\
SAWS_Openness & 28.47 & 7.52 & 33.00 & 7.33 & -2.52 & 0.014 \\
\hline
\end{tabular}

Figure-2.Mean score differences of predispositions for safe $(n=51)$ versus risk $(n=26)$ option taken by the participants $(\mathrm{N}=77)$ in second in the trial of share market task

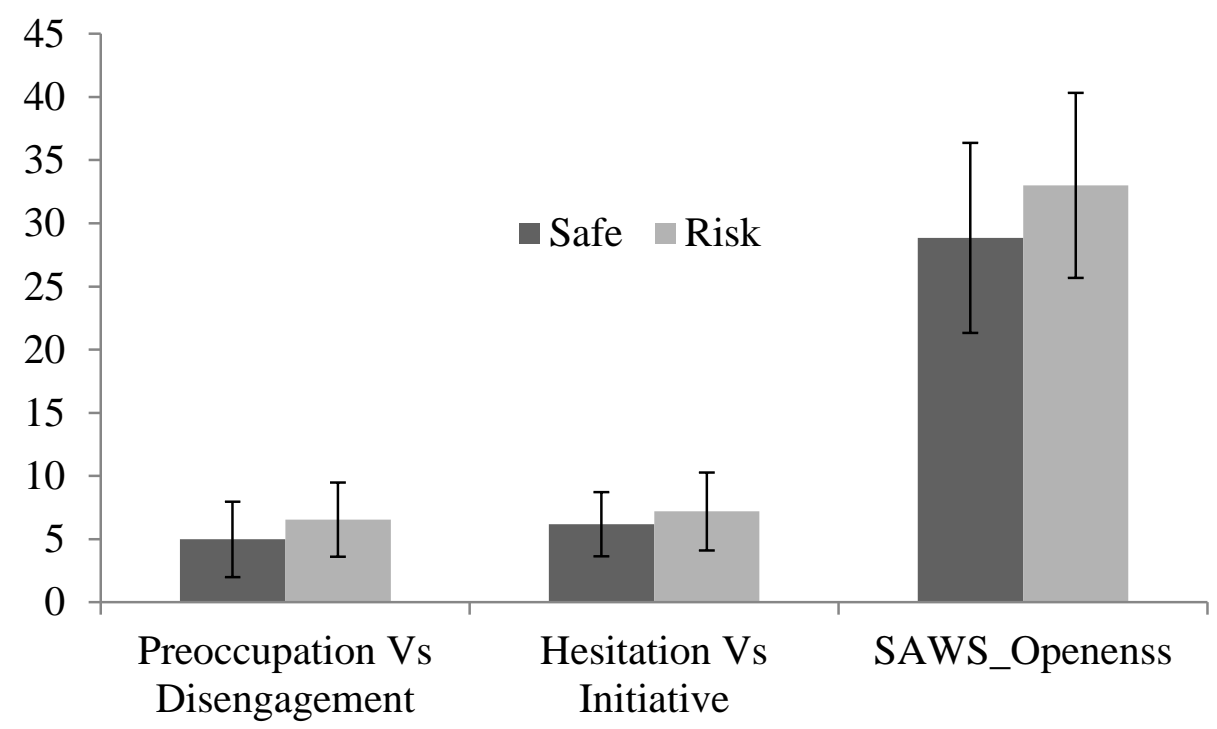


Table-3. Mean score differences of predispositions for stay $(n=53)$ versus change $(n=24)$ the previously adopted option (safe or risk) by the participants $(\mathrm{N}=77)$ after the first trial of share market task.

\begin{tabular}{|lccccccc|}
\hline & \multicolumn{2}{c}{ Stay $(\mathbf{n}=\mathbf{5 3})$} & \multicolumn{2}{c}{ Change $(\mathbf{n}=\mathbf{2 4})$} & & \\
\cline { 2 - 4 } $\begin{array}{l}\text { Personality } \\
\text { Dispositions }\end{array}$ & Mean & SD & Mean & SD & t & p-value \\
$\begin{array}{l}\text { Preoccupation vs } \\
\text { Disengagement }\end{array}$ & 5.05 & 2.98 & 6.50 & 3.01 & -1.97 & 0.053 \\
$\begin{array}{l}\text { Hesitation vs } \\
\text { Initiative }\end{array}$ & 6.58 & 2.74 & 6.38 & 2.86 & .31 & 0.760 \\
SAWS_Openness & 28.83 & 7.81 & 32.58 & 6.96 & -2.02 & 0.047 \\
\hline
\end{tabular}

Figure-3.Mean score differences of predispositions for stay $(n=53)$ versus change $(n=24)$ the previously adopted option (safe or risk) by the participants $(\mathrm{N}=77)$ after the first trial of share market task.

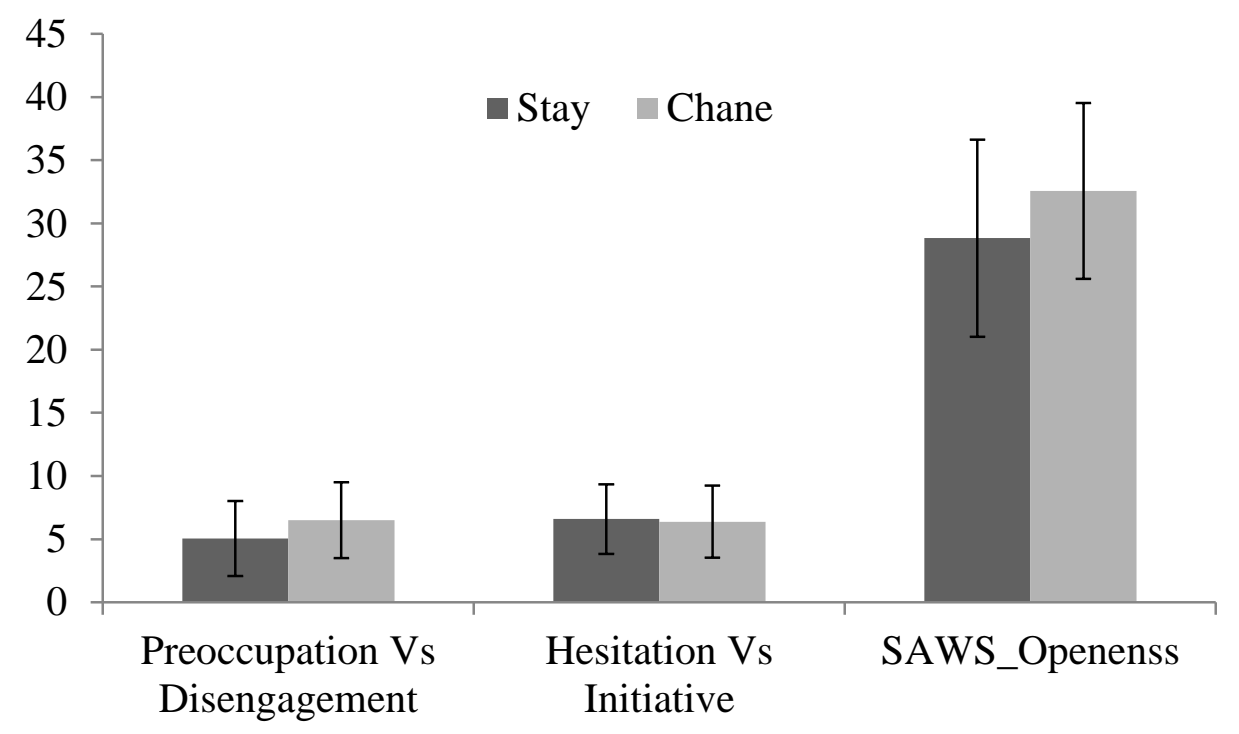


Table-4. Cross-tabulation of the option taken (safe or risk) by the participants $(\mathrm{N}=77)$ in trail one and two of share market task.

\begin{tabular}{|c|c|c|c|c|c|c|}
\hline \multicolumn{6}{|c|}{ SafeVsRisk_1 * SafeVsRisk_2 Cross tabulation } & \multirow{3}{*}{$\chi^{2}$ (p-value) } \\
\hline & & & \multicolumn{2}{|c|}{ SafeVsRisk_2 } & \multirow[b]{2}{*}{ Total } & \\
\hline & & & Safe & Risk & & \\
\hline \multirow[t]{4}{*}{ SafeVsRisk_1 } & \multirow[t]{2}{*}{ Safe } & Count & 44 & 17 & 61 & \multirow[t]{4}{*}{$0.033 *(0.04)$} \\
\hline & & $\begin{array}{l}\% \text { within } \\
\text { SafeVsRisk_1 }\end{array}$ & $72.1 \%$ & $27.9 \%$ & $100.0 \%$ & \\
\hline & \multirow[t]{2}{*}{ Risk } & Count & 7 & 9 & 16 & \\
\hline & & $\begin{array}{l}\% \text { within } \\
\text { SafeVsRisk_1 }\end{array}$ & $43.8 \%$ & $56.3 \%$ & $100.0 \%$ & \\
\hline \multicolumn{2}{|l|}{ Total } & Count & 51 & 26 & 77 & \\
\hline
\end{tabular}

Table -5 . Mean score differences of predispositions for low regret $(n=39)$ versus high regret $(\mathrm{n}=38)$ felt by the participants $(\mathrm{N}=77)$ in the second trial of share market task.

\begin{tabular}{|lcccccc|}
\hline & \multicolumn{2}{l}{ Low Regret $(\mathbf{n = 3 9})$} & \multicolumn{2}{c}{ High Regret $(\mathbf{n = 3 8})$} & & \\
\cline { 2 - 4 } $\begin{array}{l}\text { Personality } \\
\text { Dispositions }\end{array}$ & Mean & SD & Mean & SD & t & p-value \\
$\begin{array}{l}\text { Preoccupation vs } \\
\text { Disengagement }\end{array}$ & 6.46 & 3.10 & 4.52 & 2.67 & 2.93 & .005 \\
$\begin{array}{l}\text { Hesitation vs } \\
\text { Initiative }\end{array}$ & 7.48 & 2.78 & 5.52 & 2.39 & 3.31 & .001 \\
SAWS_Openness & 32.41 & 7.74 & 27.52 & 6.93 & 2.91 & .005 \\
\hline
\end{tabular}

The analysis of present work for the mean difference (as shown in table one and two) suggest that individual who look for better opportunities (even with higher risk) are higher in preoccupation vs disengagement dimensions of action orientation and openness to experiences. Not only this, but they also tried to explore other alternatives in expectation of positive outcome (as shown in table three). Further evidence of this can be seen from the cross-tabulation analysis. The analysis shows that out of 61 participants (who chose the safe option in trial one), 44 of them chose safe option again in trial two also, whereas 17 (27.9\% safe-risky) switched to risky option. Similarly, out of 16 participants (who chose risky options in trail one), 7 (43.8\% risky-safe) of them switched to safe option in trial two and nine again chose the risky option.

Further support for the argument is found where no significant difference in action orientation and openness based on regret experience in the trail one is seen. However, in trail two individuals high on preoccupation vs disengagement, hesitation vs initiative action 
orientation and openness to experience reported significantly less experience of regret than their counterpart (as reported in table five). This finding support to the argument that even after repeated failure, individuals high on action orientation and openness regulate their negative emotions better.

This finding also supports the action orientation literature. Beckman and Kuhl (1984) suggested that individuals with action orientation tend to 'spreading the alternative'. The 'spreading the alternative' suggest that the individuals with action orientation overrate the merits of any alternatives they choose to ensure that they remain committed to their decision unless crucial and unexpected information is presented. However, where literature suggest for 'action effect' (Connolly \& Zeelenberg, 2002) that action that leads to failure will cause greater regret, in present analysis no significant difference in regret experienced in trial one or two was found for whichever option the participants chose. Therefore it can be concluded that people high on action orientation and openness to experiences take risky options and explore alternatives, regulate their adverse affective reactions better, and thus approach life in ways which is wisdom development enabling. 
Table -6 .

\begin{tabular}{|c|c|c|c|c|c|c|c|c|c|c|}
\hline Variable & SM_regret2 & $\begin{array}{c}\text { Preoccupation vs } \\
\text { Disengagement }\end{array}$ & $\begin{array}{c}\text { Hesitation } \\
\text { vs } \\
\text { Initiative }\end{array}$ & $\begin{array}{l}\text { Volatality vs } \\
\text { Persistence }\end{array}$ & SAWS_EX & SAWS_EM & SAWS_R & SAWS_H & SAWS_O & SAWS_Total \\
\hline SM_regret1 & $.697^{* *}(.000)$ & $-.193(.092)$ & $-.205(.074)$ & $-.059(.609)$ & $-.077(.505)$ & $-.221(.053)$ & $-.108(.352)$ & $-.053(.649)$ & $-.146(.205)$ & $-.139(.227)$ \\
\hline SM_regret2 & 1 & $-.307^{* *}(.007)$ & $-.296^{* *}(.009)$ & $-.186(.104)$ & $-.110(.341)$ & $-.271^{*}(.017)$ & $-.215(.060)$ & $-.165(.152)$ & $-.322^{* *}(.004)$ & $-.259^{*}(.023)$ \\
\hline Preoccupation vs Disengagement & & 1 & $.308^{* *}(.006)$ & $.155(.179)$ & $-.068(.555)$ & $.250 *(.029)$ & $-.084(.466)$ & $.081(.483)$ & $.579^{* *}(.000)$ & $.195(.089)$ \\
\hline Hesitation vs Initiative & & & 1 & $.329^{* *}(.004)$ & $-.018(.875)$ & $.259^{*}(.023)$ & $.031(.787)$ & $.019(.867)$ & $.276^{*}(.015)$ & $.135(.241)$ \\
\hline Volatility vs Persistence & & & & 1 & $.010(.933)$ & $.180(.117)$ & $-.004(.972)$ & $.053(.644)$ & $.221(.053)$ & $.110(.340)$ \\
\hline
\end{tabular}

SM: share market task, EX: life experiences, EM: emotional regulation, R: reflection, H: Humor, O: openness

Figure-4. An indirect effect of Hesitation Vs Initiative on regret experience through Openness.

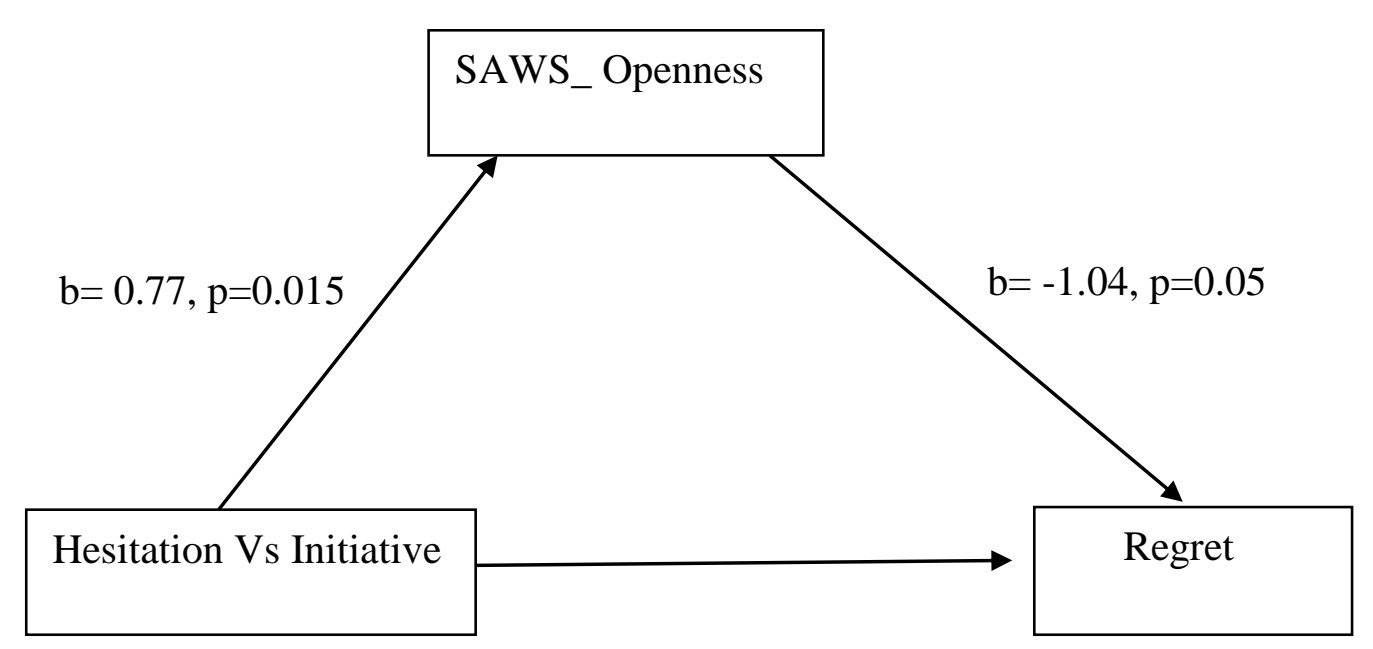

Direct effect $b=-3.28, p=0.01$

Indirect effect $b=-0.80,95 \%$ CI $[-2.06,-0.085]$ 
The answer for the third question was sought through correlation and mediation regression analysis to check the possible predictive power of personality disposition for negative affect handling. The correlation analysis suggests a significant correlation between sub-dimensions of action orientation, wisdom scale and regret experienced in trail two of decision-making task. The mediator regression analysis showed that hesitation vs. initiation (action orientation) positively openness $(b=$ $0.77, p=0.015)$ and negatively predicted regret $(b=-3.28, p=0.01)$, openness also negatively predicted regret $(b=-1 .-4, p=0.05)$. The mediator regression analysis results show that openness significantly mediates the effect of hesitation vs initiative tendency on the experience of regret, $\mathrm{b}=$ $0.80,95 \%$ BCa CI [-2.00, -.085]. The mediation effect size and Preacher \& Kelly's Kappa Squared was found to be $4 \%(\mathrm{R} 2=.04)$ and $8 \%(\mathrm{k} 2=.08)$ respectively indicating small effect size. Though the effect size is small, the result does indicate that the action orientation (hesitation vs initiative) negatively predict regret experience, similarly, openness also negatively predict regret experience. However, the interaction effect of action orientation and openness yields less negative prediction. This suggests that individual who have action orientation (hesitation vs initiative) and openness, both personality disposition experience more regret than people having only either disposition. This finding again supports the contention of this paper that individuals higher on openness or action orientation experience less regret than their counterpart but individuals who have both of these personality dispositions experience more regret (due to interaction effect).

Therefore. the findings of this paper support that individuals with action orientation and openness both the personality dispositions experience more regret yet they explore more, take the risk and as Beckman and Kuhl (1984) suggested they 'spread the alternatives'. The possible explanation for such evaluation and thus a continuation of same reactions may revolve around the theme of 'at least I tried' (Itzkin, Van Dijik, \& Azar, 2016) giving them richer experiences and more satisfaction with their life gradually leading to the personal wisdom development.

\section{Limitation and suggestion for further research:}

Though the methodology used here provides the empirical validation, still it is limited in the ecological validity and therefore complementing these results with a reflective interview or diary method will provide more holistic understanding. Similarly, demographic factors are critical in understanding wisdom development; therefore, replication of this work with complementing methodology on the diverse population on a large scale will provide the holistic insight to preexperience inclinations on the ontogenesis of wisdom. This kind of insight can help to design interventions for wisdom development. This is need of the hour as Isaac Asimov, way back in 1988 said that "The saddest aspect of life right now is that science gathers knowledge faster than society gathers wisdom", and today we need it more than ever before.

\section{Acknowledgement:}

This work is supported by Cognitive Sciecne Research Initiative (CSRI), Department of Science and Technology, Government of India. 


\section{References}

Baltes, P. B., \& Staudinger, U. M. (2000). A metaheuristic (pragmatic) to orchestrate mind and virtue toward excellence. American Psychologist, 55, 122-136. doi: 10.1037/0003-066X.55.1.122

Beckmann, J., \& Kuhl, J. (1984). Altering information to gain action control: Functional aspects of human information processing in decision making. Journal of Research in Personality, 18, 224-237.

Connolly, T. \& Zeelenberg, M. (2002). Regret in decision making. Current Directions in Psychological Science, 11, 212-216.

de Lange, M. A., \& van Knippenberg, A. (2009). To err is human: How regulatory and action orientation predict performance following errors. Journal of Experimental Social Psychology, 45, 1192-1199.

Digman, J. M. (1997). Higher-order factors of the Big Five. Journal of Personality and Social Psychology, 73, 1246-1256. doi:10.1037/0022-3514.73.6.1246

Grass J, Krieger F, Paulus P, Greiff S, Strobel A, Strobel A (2019) Thinking in action: Need for Cognition predicts Self-Control together with Action Orientation. PLOS ONE, 14(8): e0220282. https://doi.org/10.1371/journal.pone.0220282

Itzkin A, Van Dijk D and Azar OH (2016) At Least I Tried: The Relationship between Regulatory Focus and Regret Following Action vs. Inaction. Front. Psychol. 7:1684. doi: 10.3389/fpsyg.2016.01684

Jeste, D. V., Ardelt, M., Blazer, D., Kraemer, H. C., Vaillant, G., \& Meeks, T. W. (2010). Expert consensus on characteristics of wisdom: A delphi method study. The Gerontologist, 50, 668-680. doi: 10.1093/geront/gnq022

Kahneman, D. \& Riis, J. (2005). Living, and Thinking about It: Two Perspectives on Life. In Huppert, F.A., Baylis, N., \& Keverne, B. (Eds.), The Science of Well-Being, 285-304. Oxford University Press.

Kazen, M., Kaschel, R., \& Kuhl, J. (2008). Individual differences in intention initiation under demanding conditions: Interactive effects of state vs. action orientation and enactment difficulty. Journal of Research in Personality, 42, 693-715.

Kuhl, J. (1981). Motivational and functional helplessness: The moderating effect of state versus action orientation. Journal of Personality and Social Psychology, 40, 155-170.

Kuhl, J. (1994a). A theory of action and state orientation. In J. Kuhl \& J Beckmann (Eds.), Volition and personality: Action vs state orientation (pp. 9-46). Seattle: Hogrefe \& Huber.

Kuhl, J. (1994b). Action and state orientation: Psychometric properties of the action control scales (ACS-90). In J. Kuhl \& J. Beckmann (Eds.), Volition and personality: Action vs. state orientation (pp. 47-59). Gottingen: Hogrefe.

Kuhl, J. (2000). A functional-design approach to motivation and self-regulation: The dynamics of personality systems interactions. In M. Boekaerts, P.R. Pintrich, \& M. 
Zeidner, (Eds.), Handbook of self-regulation (pp. 111-169). San Diego, CA: Academic Press.

Kuhl, J., \& Goschke, T. (1994). A theory of action control: Mental subsystems, models of control, and volitional conflict-resolution strategies. In J. Kuhl \& J Beckmann (Eds.), Volition and personality: Action vs state orientation (pp. 93-124). Seattle: Hogrefe \& Huber.

Kuhl, J., \& Helle, P. (1994). Motivational and volitional determinants of depression: The degenerated-intention hypothesis. In J. Kuhl \& J Beckmann (Eds.), Volition and personality: Action vs state orientation (pp. 283-296). Seattle: Hogrefe \& Huber.

McElroy, T., \& Dowd, K. (2007). Action orientation, consistency and feeling of regret. Judgement and Decision Making, 2(6), 333-341.

McKee, P., \& Barber, C. (1999). On defining wisdom. The International Journal of Aging and Human Development, 49(2), 149-164.

Mickler, C., \& Staudinger, U. M. (2004). Manual for the assessment of self-related wisdom. Bremen, Germany: International University Bremen.

Mickler, C., \& Staudinger, U. M. (2008). Personal wisdom: Validation and age-related differences of a performance measure. Psychology and Aging, 23, 787-799. doi:10.1037/a0013928

Moss, S. (2016). Action versus state orientation. Retrieved from https://www.sicotests.com/psyarticle.asp?id=208\#: :text=Dimensions,instance\%2Daf ter\%20failures\%20or\%20threats on 10 September 2020.

Sharma, A., \& Dewangan (2018). Indian Socio-Cultural Conception of Wisdom: Does it Follow Universal Understanding? Journal of Psychology, 6(1), 5-19

Sharma, A., \& Dewangan, R. L. (2017). Can wisdom be fostered: Time to test the model of wisdom. Cogent Psychology, 4(1), 1-17. https://doi.org/10.1080/23311908.2017.1381456

Staudinger, U. M., \& Glück, J. (2011). Psychological wisdom research: Commonalities and differences in a growing field. Annual Review of Psychology, 62, 215-241. doi: 10.1146/annurev.psych.121208.131659

Staudinger, U. M., \& Kunzmann, U. (2005). Positive adult personality development: Adjustment and/or growth? European Psychologist, 10, 320-329. doi:10.1027/10169040.10 .4 .320

Staudinger, U. M., Dörner, J., \& Mickler, C. (2005). Wisdom and personality. In R. Sternberg \& J. Jordan (Eds.), A handbook of wisdom: Psychological perspectives (pp. 191-219). NewYork, NY: Cambridge University Press.

Stiensmeier-Pelster, J. (1994). Choice of decision-making strategies and action versus state orientation. In J. Kuhl \& J. Beckmann (Eds.), Volition and personality (pp. 167-176). Gottingen, Germany: Hogrefe \& Huber. 
Van Putten, M., Zeelenberg, M., \& Van Dijk, E. (2009). Dealing with missed opportunities: Action vs state orientation moderates inaction inertia. Journal of Experimental Social Psychology, 45, 808-815.

Webster, J. D. (2007). Measuring the character strength of wisdom. The International Journal of Aging and Human Development, 65, 163-183. doi: 10.2190/AG.65.2.d

Webster, J. D. (2013). Identity, wisdom, and critical life events in younger adulthood. In J.Sinnott (Ed.), Positive psychology: Advances in understanding adult motivation (pp. 61-77). New York: Springer.

Weststrate, N. M., \& Glück, J. (2017). Hard-earned wisdom: Exploratory processing of difficult life experience is positively associated with wisdom. Developmental Psychology, 53, 800-814. doi: 10.1037/dev0000286

Wink, P., \& Staudinger, U. M. (2015). Wisdom and psychosocial functioning in later life. Journal of Personality, 84, 306-318. doi: 10.1111/jopy.12160

Yang, S. Y. (2008). A process view of wisdom. Journal of Adult Development, 15, 62-75.

Zeelenberg, M., Nijstad, B. A., Van Putten, M., \& Van Dijk, E. (2006). Inaction inertia, regret and valuation: A closer look. Organizational Behavior and Human Decision Processes, 101, 89-104. 